\title{
Nerve Growth Factor Enhances Dendritic Arborization of Sympathetic Ganglion Cells in Developing Mammals
}

\author{
William D. Snider \\ Departments of Neurology and Neurological Surgery and Anatomy and Neurobiology, Washington University School of \\ Medicine, St. Louis, Missouri 63110
}

\begin{abstract}
Recent observations have suggested that the dendritic arbors of sympathetic ganglion cells may be regulated by interactions with their peripheral targets (Voyvodic, 1987a; Yawo, 1987). In order to assess a potential mechanism for such interactions, I have investigated the effects of the target-derived trophic molecule for sympathetic ganglion cells on the development of dendrites in the rat superior cervical ganglion. Systemic treatment of neonatal animals with NGF for 1 or 2 weeks results in a striking expansion of ganglion cell dendritic arbors, as revealed by intracellular staining with HRP. During this period, neurons in treated animals extend new primary dendrites, and the length and branching of existing dendrites are increased compared to age-matched controls. These results support the idea that targets may regulate ganglion cell arbors via elaboration of NGF, and suggest an explanation for the correlation between animal size and dendritic complexity noted in several recent studies (Purves and Lichtman, 1985a; Snider, 1987; Voyvodic, 1987a).
\end{abstract}

Because the majority of synapses in the mammalian nervous system are found on dendrites, the regulation of dendritic arbors is of critical importance to neural organization. To some degree, dendritic arbors appear to be specified at early developmental stages by intrinsic genetic mechanisms (Banker and Cowan, 1979; Kriegstein and Dichter, 1983; Honig and Hume, 1986). However, arbors are also influenced by extrinsic factors, particularly neural connections (Grant 1968; Sumner and Watson, 1971; Benes et al., 1977; Parks, 1981; Deitch and Rubel, 1984). In the case of sympathetic ganglia, where both afferent and efferent projections are accessible and easily interrupted, the advent of intracellular staining has allowed a detailed examination of the influence of neural connections on dendritic arborization. Such studies have revealed that ganglion cell arbors are not appreciably influenced by afferent fibers, either during development or in maturity (McLachlan, 1974; Smolen and Beaston-Wimmer, 1986; Voyvodic, 1987a). On the other hand, arbors retract after axotomy and re-expand in association with reinnervation of targets (Purves, 1975; Yawo, 1987). These findings have sug-

Received Sept. 1, 1987; revised Nov. 12, 1987; accepted Nov. 13, 1987.

This work was supported by a Clinical Investigator Development Award to W.S. and NIH Grants 11699 and 18629 to D. Purves. I thank D. Purves and E. M. Johnson, Jr., for advice and encouragement during the course of this project and Mary Unangst for typing the manuscript. Helpful comments were made by J. Sanes, J. Voyvodic, and C. Forehand.

Correspondence should be addressed to William D. Snider, Department of Neurology, Washington University School of Medicine, 660 South Euclid, Box 8111 , St. Louis, MO 63110.

Copyright (C 1988 Society for Neuroscience $0270-6474 / 88 / 072628-07 \$ 02.00 / 0$ gested that dendritic arbors of sympathetic ganglion cells are primarily dependent on efferent connections, and thus may be regulated by interactions with their peripheral targets (Voyvodic, 1987a; Yawo, 1987). Further support for a target-derived influence on the arborization of sympathetic neurons has come from experiments showing a correlation between arbor complexity and target size during development (Voyvodic, 1987a) across species (Purves and Lichtman, 1985a; Purves et al., 1986; see also Snider, 1987), and after experimentally induced changes (Voyvodic, 1987b).

Neuronal interactions with targets are thought to be mediated by the uptake and retrograde transport of neurotrophic molecules (Harris, 1974; Purves and Lichtman, 1985b). That trophic molecules might affect dendritic arborization is suggested by the striking propensity of the prototype of these molecules, NGF, to promote neurite outgrowth from susceptible neurons in vivo and in vitro (for reviews, see Levi-Montalcini and Angeletti, 1968; Thoenen and Barde, 1980). Previous investigations have established that administration of NGF to developing mammals leads to profuse branching of the axons of sympathetic ganglion cells and expansion of their terminal arborizations in the periphery (Levi-Montalcini and Cohen, 1956; Olson, 1967; LeviMontalcini and Angeletti, 1968). However, the influence of NGF on dendritic arbors has not been studied in a systematic manner. The purpose of the present study, therefore, was to ask whether administration of NGF affects dendritic arbors in a manner consistent with the idea that this molecule may regulate dendritic development in sympathetic ganglia.

\section{Materials and Methods}

NGF was administered daily to newborn Sprague-Dawley rats beginning on postnatal day 1 or 2 . Purified $\beta$ subunit of mouse NGF (kindly provided by E. M. Johnson, Jr. and P. Osborne) was dissolved in saline and injected subcutaneously in a dosage of $5 \mathrm{mg} / \mathrm{kg}$. A similar dose is known to increase sympathetic ganglion cell size and enhance synthesis of transmitter enzymes (Thoenen et al., 1971). Animals were treated for either 7 or $14 \mathrm{~d}$ and compared with controls at these same ages.

For intracellular staining, the superior cervical ganglia were removed and pinned in a chamber superfused with an oxygenated mammalian saline. Neurons were impaled with triangular glass electrodes (Glass Co. of America) filled with a $4 \%$ solution of HRP (Sigma, type 6 ). The HRP was introduced into the cell by iontophoresis and the reaction product was visualized by the pyrocatechol-phenylenediamine method (Hanker et al., 1977; for details, see Purves and Hume, 1981; Forehand and Purves, 1984). Stained neurons were viewed at $300 \times$ in whole-mount preparations (Fig. 1) and traced with the aid of a camera lucida. Dendritic and axonal processes were distinguished using established criteria (Purves and Hume, 1981). Dendrites had numerous short processes arising from the main shaft and branched into secondary and tertiary segments relatively close to the cell soma (Fig. 1). The axon was readily identified as a smooth, thick process that usually could be followed for 


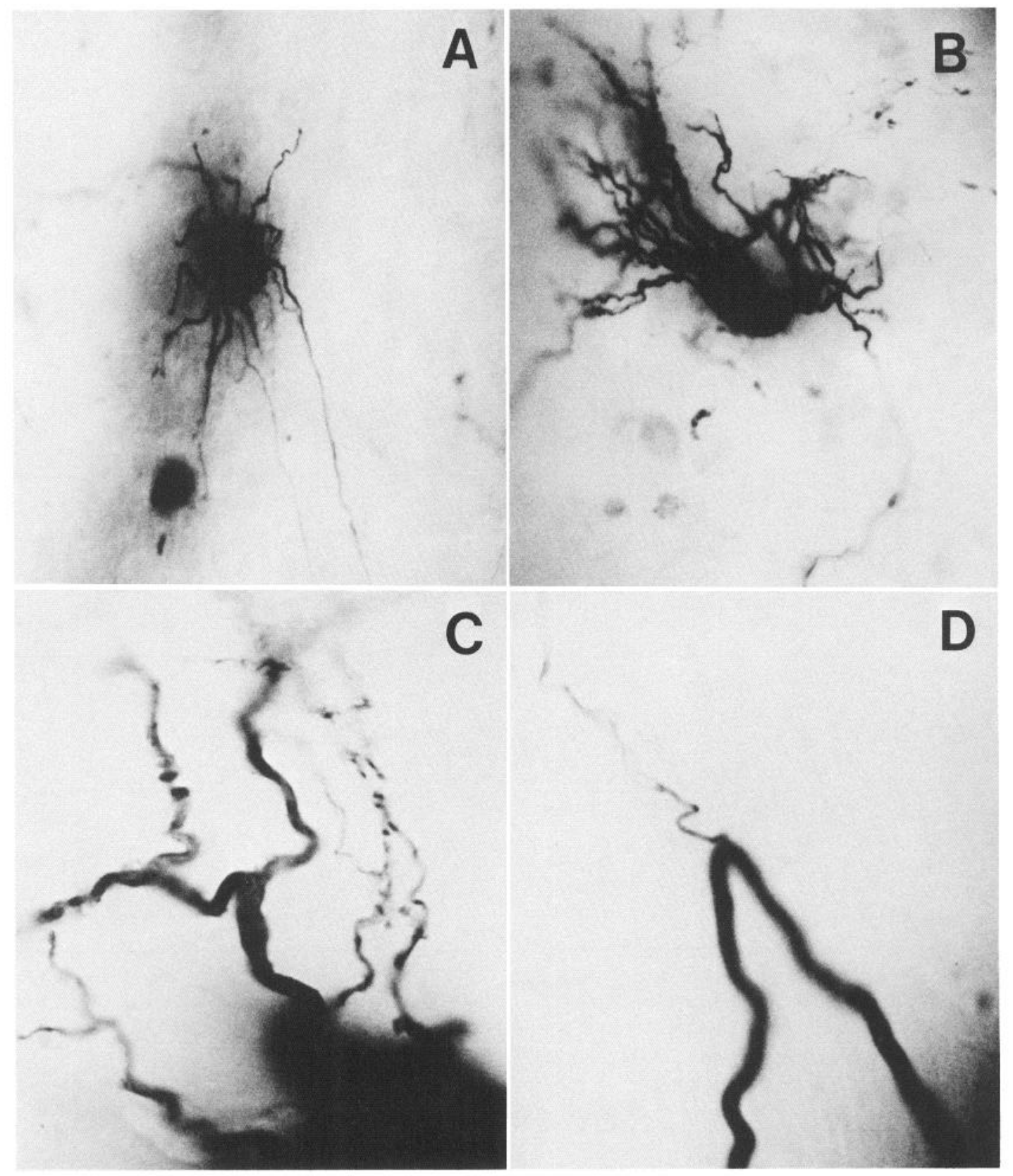

Figure 1. Photomicrographs of representative superior cervical ganglion cells stained with HRP and viewed in ganglion whole-mounts. $A$, Neuron from a control animal 2 weeks old. This cell had 8 primary dendrites and a total dendritic length of $919 \mu \mathrm{m}$. $B$, Neuron from an animal treated for 2 weeks with NGF. This cell had 12 primary dendrites and total dendritic length of $2328 \mu \mathrm{m}$. $C$, High-power view of representative dendritic processes. Note branching near the soma (bottom right) and irregularities along the shafts. $D$, High-power view of a representative axon in an animal treated with NGF. The axon surface is smooth and one fine branch is elaborated. Such axon branches are not seen in controls.

at least several hundred microns and frequently could be seen exiting the ganglion via a postganglionic nerve. In control ganglia, neurons invariably possessed a single axon, whereas a few cells in the NGF groups had 2 . Also in the NGF group, axons frequently (approximately $50 \%$ ) elaborated branches within the ganglion, a feature not seen in controls (Fig. 1). Occasional processes in treated animals could not be clearly categorized and were not included in the quantitative analysis.

The arbor of each neuron was assessed by 4 measures of dendritic complexity. The number of primary dendrites was determined by viewing the cells at $480 \times$ in multiple focal planes. A primary dendrite was defined as any process extending from the soma a distance greater than the cell diameter. Total dendritic lengths were measured from the camera lucida tracings with the aid of a digitizing tablet and a general purpose program for neural imaging (Voyvodic, 1986). The radius of a circle incorporating the entire arbor was measured as an indicator of process length. Finally, the extent of branching was determined by counting the number of branches crossing a 50\% circle (Scholl, 1953).

All well-stained neurons were analyzed. At 1 week, 47 neurons from 6 ganglia in NGF-treated animals were compared with 39 neurons in 10 ganglia from controls. Morphologic data on some cells in the 1 week control group are from a previous study (Snider, 1986). At 2 weeks, 43 cells in 6 ganglia from NGF-treated animals were compared with 36 cells in 8 ganglia from controls.

\section{Results}

The dendritic arbors of sympathetic ganglion cells are quite rudimentary in neonatal animals (Fig. 2; see also Snider, 1986; Voyvodic, 1987a). At 1 week of age, the mean total dendritic 


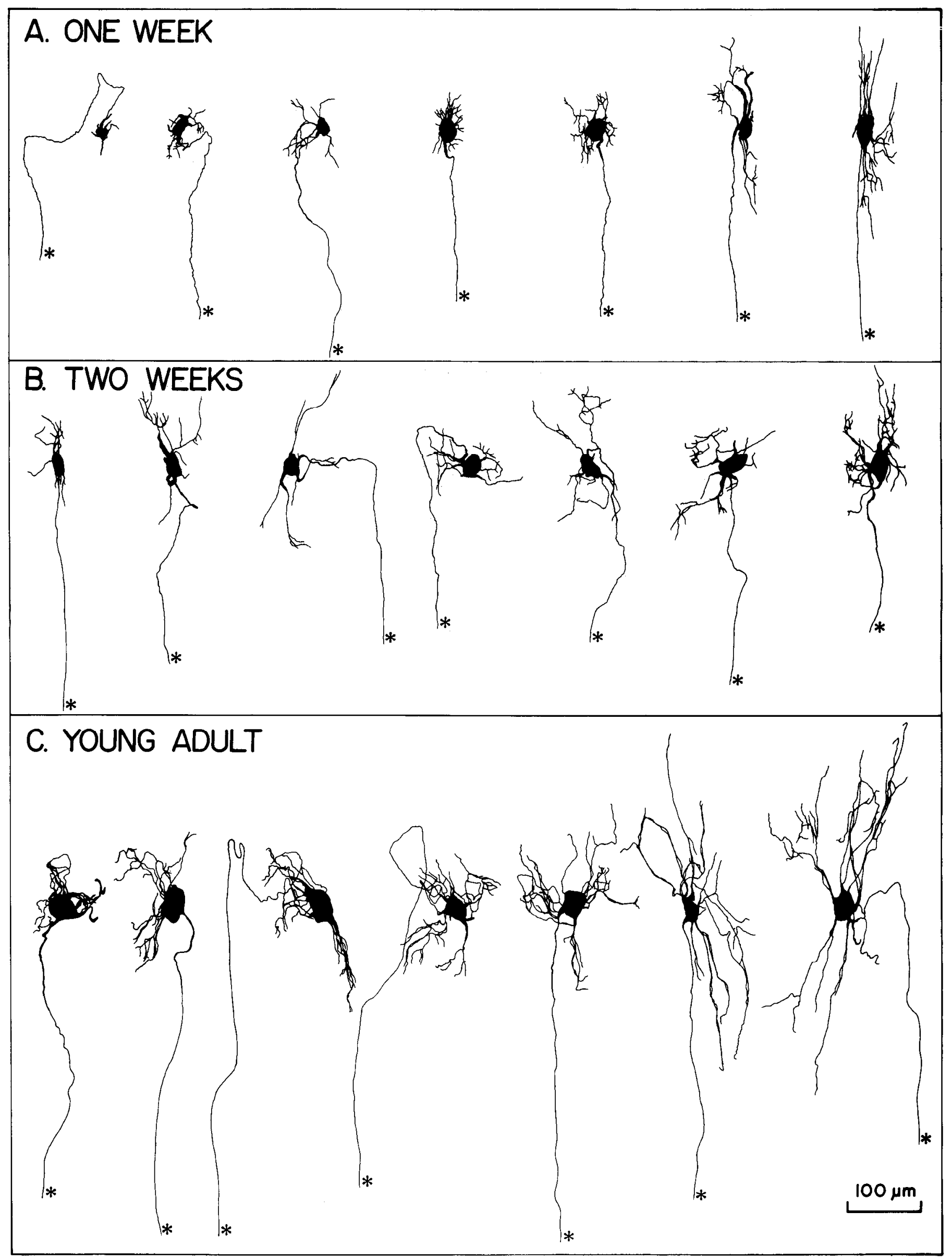




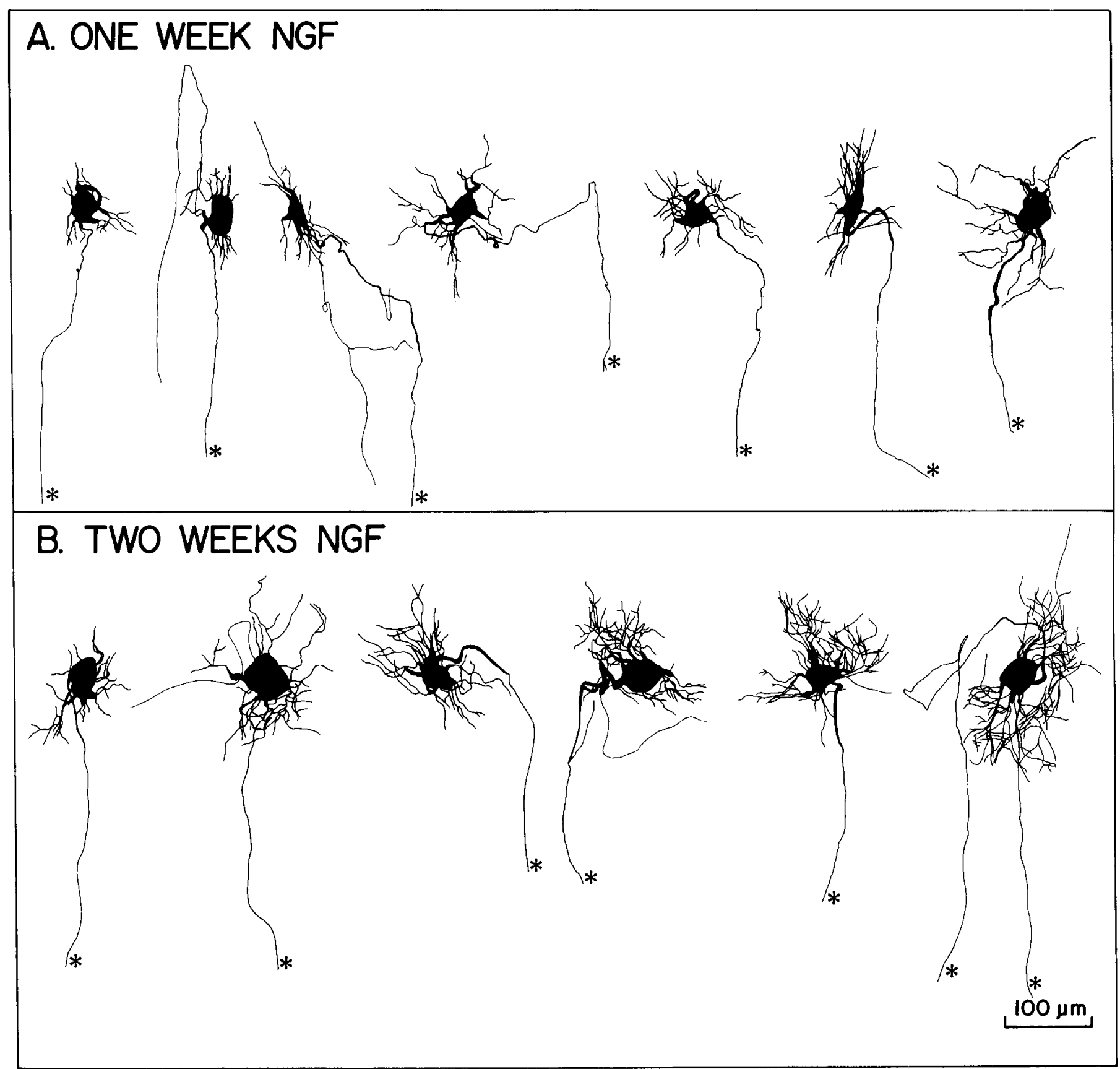

Figure 3. Effects of daily administration of NGF on dendritic arbors of sympathetic ganglion cells. The scale is the same as Figure 2. A, One week of treatment. $B$, Two weeks of treatment. Neurons were arranged in order of increasing total dendritic length, and every seventh neuron selected. Neurons 2 and 3 in $A$ and 4 and 6 in $B$ exhibit axonal branches. Neuron 2 in $B$ has a process (exiting to left) that could not be clearly classified. Such processes were not included in the calculation of total dendritic length.

length in the superior cervical ganglion is only about one-third that of young adults (see Table 1). Ganglion cell arbors expand rapidly in the first few weeks after birth. Thus, almost $200 \mu \mathrm{m}$ of dendritic length is added between postnatal weeks 1 and 2 (Table 1). Measures of process length and branching increase in parallel with increases in total dendritic length during this pe- riod. However, one important component of arbor geometry, the number of primary dendrites, does not change during normal postnatal development (Fig. 2; Table 1). This finding raises the possibility that various aspects of dendritic growth may be differentially regulated (see below; see also Voyvodic, 1987a).

Administration of NGF had a pronounced effect on dendritic

Figure 2. Normal development of sympathetic ganglion cells over the first 8 weeks of life. For $A-C$, camera lucida drawings were arranged in order of increasing total dendritic length and every sixth $(A)$ or fifth $(B)$ neuron was selected. ( $C$ is from Snider, 1986, and is shown for purposes of comparison with neurons from the animals treated with NGF for 2 weeks.) 
Figure 4. Histograms of dendritic lengths of control (left) and NGF-treated (right) animals. There is considerable variability in both the treatment and control groups.

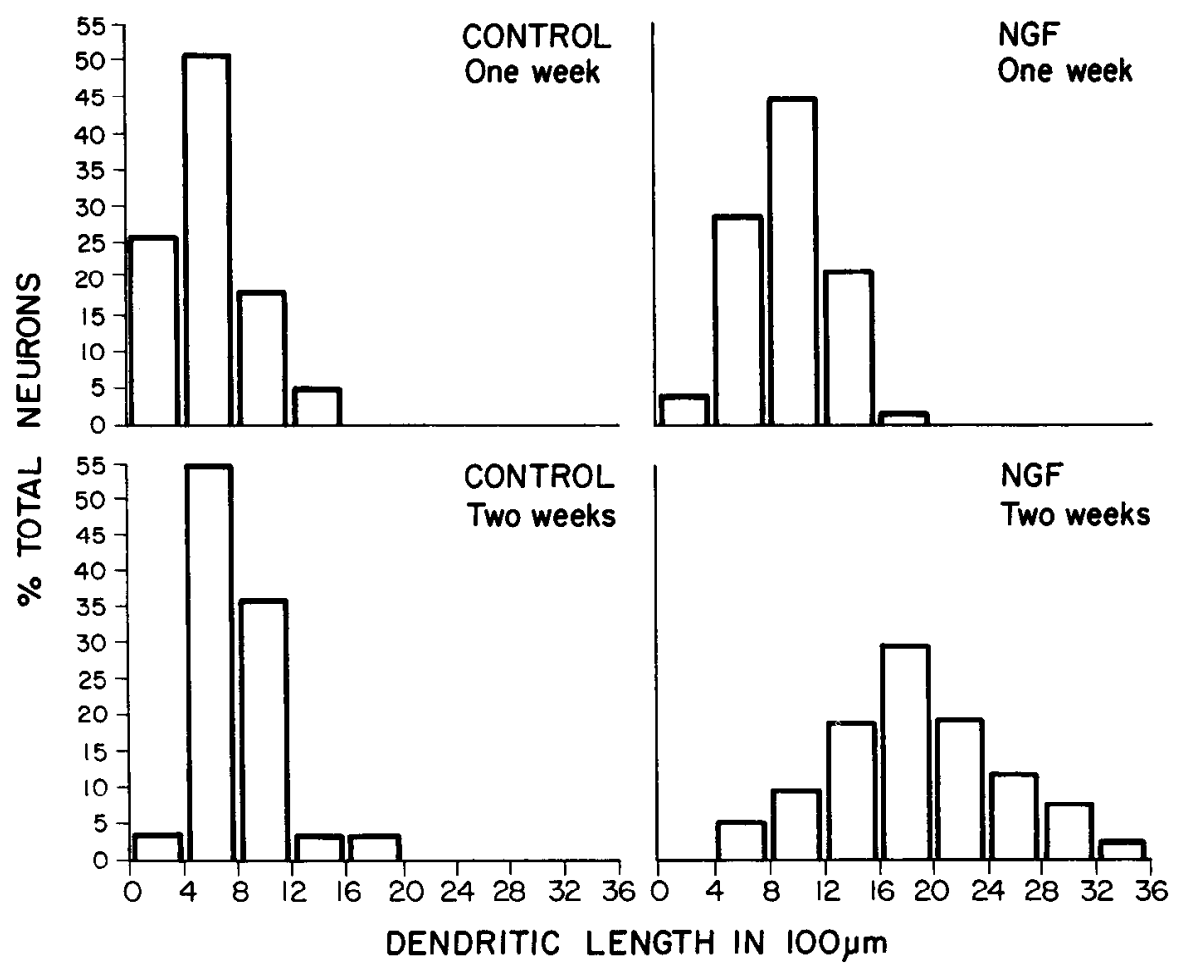

arborization (Fig. 1; cf. Figs. 2, 3). After just 1 week of treatment, there were highly significant increases in process length, extent of branching, and total dendritic length (Table 1, Fig. 4). After 2 weeks, the mean total dendritic length of ganglion cells in treated animals was more than twice that of control neurons (1885 $\mu \mathrm{m}$ compared to $779 \mu \mathrm{m}$ ) and similar to neurons in young adults 8 weeks of age. Since rat superior cervical ganglion cells have a mean total dendritic length of $287 \mu \mathrm{m}$ on the day of birth (Voyvodic, 1987a), these data indicate that neurons in NGFtreated animals extend dendrites at about 3 times the rate of controls over the 2 week period. Interestingly, neurons appeared to be at least as responsive during the second week of treatment as during the first.

In addition to its effects on other measures of complexity, treatment with NGF led to a large increase in the number of primary dendrites (cf. Figs. 2, 3; Table 1). In controls, ganglion cells had a mean of about 7 primary dendrites at 1 and 2 weeks, with 13 being the maximum elaborated by any neuron. In contrast, treated neurons at 1 week had a mean of almost 9 primary dendrites. After 2 weeks of NGF administration, neurons had a mean of 13 primary dendrites, with some neurons possessing more than 20 . This increase in the number of primary dendrites caused ganglion cells in treated animals to look quite different from cells of equivalent total dendritic length in control animals 8 weeks of age (cf. Figs. 2, 3).

Finally, as has been apparent from the earliest days of work with this molecule, NGF has a remarkable effect on the size of sympathetic ganglion cell bodies (cf. Figs. 2, 3; Table 1). After 1 week of treatment, soma diameter was increased by almost $25 \%$ compared to controls. After 2 weeks, soma diameter in treated animals was $30 \%$ more than in 2-week-old controls and $20 \%$ more than in young adult animals.

\section{Discussion}

The results described here demonstrate that exogenous NGF enhances the dendritic arborization of developing sympathetic ganglion cells. Neurons in treated animals had more primary processes than controls, and the length and ramification of dendrites were increased substantially. Significant effects were noted after just 1 week of treatment. After 2 weeks, the overall com-

Table 1. Morphological characteristics of superior cervical ganglion cells in control and NGF-treated animals

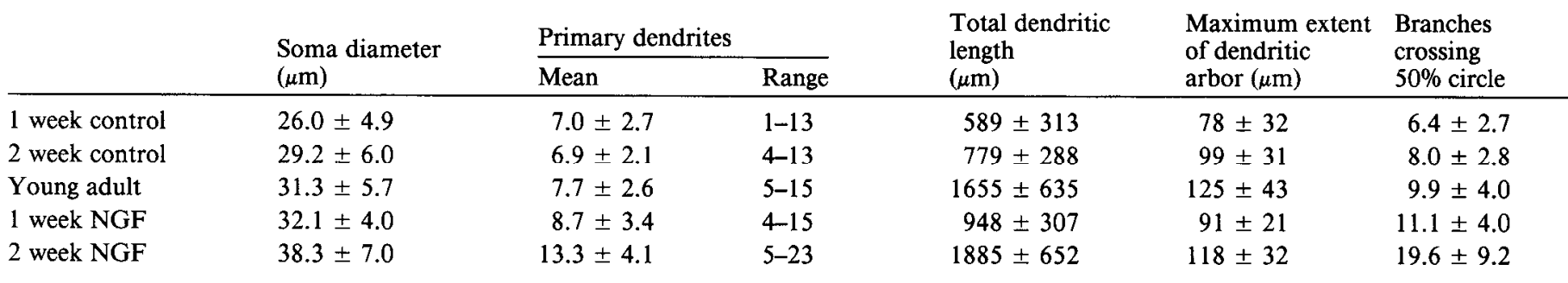

All values except range of primary dendrites are given as means \pm SDs. Results were analyzed using Student's $t$ test. The differences in number of primary dendrites and maximum extent of dendritic arbor between the 1 week control and NGF groups were significant at $p<0.01$. The difference in maximum extent of the arbor between the 2 week control and NGF groups was significant at $p<0.005$. All other differences between control and NGF groups were highly significant (at least $p<$ 0.001 ). Values for young adult are from Snider (1986). 
plexity of treated neurons was more than twice that of controls and similar to the total extent of ganglion cell dendrites in animals 8 weeks of age.

In comparing the dendritic growth induced by NGF to the growth of arbors that occurs during normal development, important similarities and differences are apparent. Normally, the number of primary dendrites is set by the first postnatal week, and arborization proceeds by increases in length and branching of existing processes (see aiso Snider, 1986; Voyvodic, 1987a). A posssible explanation for this pattern of arborization is that sympathetic neurons either cannot respond to target-derived factors by generating new primary processes or respond in this way only during embryonic life. My results make this idea unlikely. Exogenous NGF promotes the growth and branching of existing dendrites, as occurs during normal postnatal development. In addition, neurons extend new primary processes under the influence of NGF even in the postnatal period. This ability to change normal geometry also indicates that NGF does more than simply accelerate a preexisting developmental program.

My results imply that arbors of sympathetic ganglion cells may be influenced by target-derived NGF during normal development. Although it is not known how NGF acts after systemic administration, it is likely that it mimics the effects of target-derived factor. Previous investigations have established that exogenous NGF can prevent naturally occurring cell death (like a supernumerary target) and maintain ganglion cells after separation from their targets by axotomy (Hendry and Campbell, 1976; Hamburgcr and Yip, 1984; Yip et al., 1984). Systemic NGF may exert additional effects, however, by local action on neurites in the ganglion (see Campenot, 1977, 1982a, b).

The demonstration that dendritic arbors of autonomic ganglion cells are influenced by trophic molecules may provide an explanation for correlations between arbor complexity and target size noted in recent investigations. The dendritic complexity of rat superior cervical ganglion cells increases in parallel with increasing body weight (and target size) for much of the life of the animal-far beyond the time normally considered to be the period of development (Voyvodic, 1987a). Furthermore, experimental increases and decreases in the amount of target tissue innervated by individual ganglion cells during development lead to corresponding changes in their dendritic complexity (Voyvodic, 1987b). Finally, the dendritic arbors of homologous autonomic ganglion cells in closely related species of differing size exhibit systematic differences in length and complexity that are correlated with body weight (Purves and Lichtman, 1985a; Purves et al., 1986; Snider, 1987). As the amount of trophic factor produced by a target organ presumably bears some relationship to its size, the ability of NGF to influence arbors provides a plausible link between the dendritic complexity of innervating neurons and the size of peripheral targets.

These results may also have an important implication for the organization of peripheral motor systems. Experiments that have examined the morphology and innervation of autonomic ganglion cells have shown that the number of innervating axons (preganglionic convergence) is closely matched to dendritic complexity in maturity (Purves and Hume, 1981; Purves and Lichtman, 1985a; Snider, 1987). Factors that regulate the morphology of ganglion cells will therefore have a significant influence on their pattern of innervation. Although the effects of NGF on preganglionic convergence have not yet been studied, on the basis of the present results, NGF might be expected to influence the number of inputs to sympathetic neurons. In sup- port of this suggestion, NGF administered to neonatal rats results in an increase in the number of axons in the cervical sympathetic trunk and in the density of synaptic boutons in the superior cervical ganglion (Schäfer et al., 1983). Thus, both the morphology and innervation of sympathetic ganglion cells may be matched to the size of their peripheral targets via the uptake of NGF.

\section{References}

Banker, G. A., and W. M. Cowan (1979) Further observations on hippocampal neurons in dispersed cell culture. J. Comp. Neurol. 187: 469-494.

Benes, F. M., T. N. Parks, and E. W. Rubel (1977) Rapid dendritic atrophy following deafferentation: An EM morphometric analysis. Brain Res. 122: 1-13.

Campenot, R. B. (1977) Local control of neurite development by nerve growth factor. Proc. Natl. Acad. Sci. USA 74: 4516-4519.

Campenot, R. B. (1982a) Development of sympathetic neurons in compartmentalized cultures. I. Local control of neurite growth by nerve growth factor. Dev. Biol. 93: 1-12.

Campenot, R. B. (1982b) Development of sympathetic neurons in compartmentalized cultures. II. Local control of neurite survival by nerve growth factor. Dev. Biol. 93: 13-21.

Deitch, J. S., and E. W. Rubel (1984) Afferent influences on brain stem auditory nuclei of the chicken: The course and specificity of dendritic atrophy following deafferentation. J. Comp. Neurol. 229: 66-79.

Forehand, C. J., and D. Purves (1984) Regional innervation of rabbit ciliary ganglion cells by terminals of preganglionic axons. J. Neurosci. 4: $1-12$.

Grant, G. (1968) Silver impregnation of degenerating dendrites, cells and axons central to axonal transection II. A Nauta study on spinal motor neurons in kittens. Exp. Brain Res. 6: 284-293.

Hamburger, V., and J. W. Yip (1984) Reduction of experimentally induced neuronal death in spinal ganglia of the chick embryo by nerve growth factor. J. Neurosci. 4: 767-774.

Hanker, J. S., P. E. Yates, C. B. Metz, and A. Rustioni (1972) A new specific, sensitive, and non-carcinogenic reagent for the demonstration of horseradish peroxidase. Histochem. J. 9: 789-792.

Harris, A. J. (1974) Inductive functions of the nervous system. Annu. Rev. Physiol. 36: 251-305.

Hendry, I. A., and J. Campbell (1976) Morphometric analysis of rat superior cervical ganglion after axotomy and nerve growth factor treatment. J. Neurocytol. 5: 351-360.

Honig, M. C., and R. I. Hume (1986) Fluorescent carbocyanine dyes allow living neurons of identified origin to be studied in long-term cultures. J. Cell Biol. 103: 171-187.

Kriegstein, A. N., and M. A. Dichter (1983) Morphological classification of rat cortical neurons in cell culture. J. Neurosci. 3: 16341647.

Levi-Montalcini, R., and P. U. Angeletti (1968) Nerve growth factor. Physiol. Rev. 48: 619-628.

Levi-Montalcini, R., and S. Cohen (1956) In-vitro and in-vivo effects of a nerve growth stimulating agent isolated from snake venom. Proc. Natl. Acad. Sci. USA 42: 695-699.

McLachlan, E. M. (1974) The formation of synapses in mammalian sympathetic ganglia reinnervated with preganglionic or somatic nerves. J. Physiol. (Lond.) 237: 217-242.

Olson, L. (1967) Outgrowth of sympathetic adrenergic neurons in mice treated with nerve growth factor. Z. Zellforsch. Mikrosk. Anat. 81: 155-173.

Parks, T. N. (1981) Changes in the length and organization of nucleus laminaris dendrites after unilateral otocyst ablation in chick embryos. J. Comp. Neurol. 202: 47-57.

Purves, D. (1975) Functional and structural changes in mammalian sympathetic neurones following interruption of their axons. J. Physiol. (Lond.) 252: 429-463.

Purves, D., and R. I. Hume (1981) The relation of postsynaptic geometry to the number of presynaptic axons that innervate autonomic ganglion cells. J. Neurosci. 1: 441-452.

Purves, D., and J. Lichtman (1985a) Geometrical differences among homologous neurons in mammals. Science 228: 298-302. 
Purves, D., and J. W. Lichtman (1985b) Principles of Neural Development, Sinauer, Sunderland, MA.

Purves, D., E. Rubin, W. D. Snider, and J. Lichtman (1986) The relation of animal size to convergence, divergence and neuronal number in peripheral sympathetic pathways. J. Neurosci. 6: 158-163.

Schäfer, T., M. E. Schwab, and H. Thoenen (1983) Incrcased formation of preganglionic synapses and axons due to a retrograde transsynaptic action of nerve growth factor in the rat sympathetic nervous system. J. Neurosci. 3: 1501-1510.

Scholl, D. A. (1953) Dendritic organization in the neurons of the visual and motor cortices of the cat. J. Anat. 87: 387-406.

Smolen, A., and P. Beaston-Wimmer (1986) Dendritic development in the rat superior cervical ganglion. Dev. Brain Res. 29: 245-252.

Snider, W. D. (1986) Rostrocaudal differences in dendritic growth and synaptogenesis in rat sympathetic chain ganglia. J. Comp. Neurol. 244: 245-253.

Snider, W. D. (1987) The dendritic complexity and innervation of submandibular neurons in five species of mammals. J. Neurosci. 7 : $1760-1768$.

Sumner, B. E. H., and W. E. Watson (1971) Retraction and expansion of the dendritic tree of motor neurons of adult rats induced in vivo. Nature 233: 273-275.
Thoenen, H., and Y.-A. Barde (1980) Physiology of nerve growth factor. Physiol. Rev. 60: 1284-1335.

Thoenen, H. P., P. U. Angeletti, R. Levi-Montalcini, and R. Kettler (1971) Selective induction of tyrosine hydroxylase and dopamine $\beta$-hydroxylase in rat superior cervical ganglia by nerve growth factor. Proc. Natl. Acad. Sci. USA 68: 1598-1602.

Voyvodic, J. (1986) A general purpose image processing language (IMAGR) facilitates visualization of neuronal structures in fixed tissues and in vitro. Soc. Neurosci. Abstr. 12: 390.

Voyvodic, J. (1987a) Development and regulation of dendrites in the rat superior cervical ganglion: Influence of preganglionic innervation. J. Neurosci. 7: 904-912.

Voyvodic, J. (1987b) Dendritic geometry of sympathetic ganglion cells is regulated by postganglionic target size. Soc. Neurosci. Abstr. 13: 574.

Yawo, H. (1987) Changes in the dendritic geometry of mouse superior cervical ganglion cells following postganglionic axotomy. J. Neurosci. 7: 3703-3711.

Yip, H. K., K. M. Rich, P. A. Lampe, and E. M. Johnson, Jr. (1984) The effects of nerve growth factor and its antiserum on the postnatal development and survival after injury of sensory neurons in rat dorsal root ganglia. J. Neurosci. 4: 2986-2992. 